\title{
O CONTO MODERNO DE KATHERINE MANSFIELD
}

Carlos Magno Gomes*

Resumo: Este artigo apresenta um estudo da fragmentação espaçotemporal do conto "Bliss", de Katherine Mansfield. Sua técnica explora as marcas do conto de atmosfera por meio do ritmo poético enxuto e do imprevisivel, técnicas próprias da literatura inglesa moderna. Na análise, ressalta-se o deslocamento espaçotemporal da protagonista por seus dilemas pessoais em meio a valores de uma sociedade londrina fútil e conversadora. Metodologicamente, aplicam-se os conceitos de literatura moderna, de Virginia Woolf, de devaneio, de Gaston Bachelard, e de heterotopia, de Michel Foucault.

Palavras-chave: Conto moderno. Literatura inglesa. Katherine Mansfield.

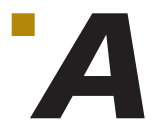

literatura inglesa moderna produziu modelos literários sofisticados quando fez experimentações estéticas radicais a partir da fragmentação temporal. Entre os escritores que mais ganharam notoriedade mundial estão James Joyce, Virginia Woolf e Katherine Mansfield. Particularmente, as duas escritoras mantiveram contato durante o desenvolvimento de seus textos experimentais no final da segunda década do século XX. Além disso, elas escreveram críticas literárias para diferentes jornais ingleses. Nessa dupla função, de escritora e de crítica literária, debateram e fizeram reflexões sobre as inovações que eram necessárias para a produção de um estilo moderno.

Com esse intuito, tanto Mansfield como Woolf investiram na narrativa fragmentada sem grandes acontecimentos, dando destaque para o desenvolvimento interno das personagens que passavam por um deslocamento pessoal em um espaço de tempo pequeno. Essas marcas próprias da narrativa moderna tiveram como referência a estética do conto de atmosfera, proposta pela ficção do russo 
Anton Tchekhov. A partir dessa intertextualidade, o conto moderno deveria ter a ambição de representar a vida como um "halo iluminado" que daria às páginas literárias "flexibilidade" e "leveza" necessárias para uma literatura que se adequasse às novas situações culturais desse periodo (LEHMANN, 1989, p. 47-48).

Incorporando alguns elementos da estética de Tchekhov, a narrativa de Mansfield ganhou um estilo próprio depois de muita experimentação com elementos rítmicos da música e com a incorporação de elementos poéticos. Esse processo de criação literária, por ser complexo e denso, teve seus altos e baixos e, muitas vezes, não foi reconhecido por seus pares. Mas, desde o início, seu estilo teve diversos leitores apaixonados. Entre eles, destaca-se o perspicaz olhar de Virginia Woolf, que entre admiração e ciúmes considerava Mansfield a maior contista de sua época.

Partindo dos contatos entre Katherine Mansfield e da proposta de ficção moderna sugerida por Virginia Woolf, este artigo está dividido em duas partes para defender a hipótese de que o processo de introspecção psicológica da personagem central do conto "Bliss" (1920) passa por um deslocamento espaçotemporal que interliga as preocupações de renovações estéticas com a de contextualizar os costumes da sociedade londrina. Tal preocupação dupla é uma marca do conto moderno de Mansfield.

$\mathrm{Na}$ primeira parte deste ensaio, investiga-se como a busca de um estilo moderno foi articulada pela crítica literária e pelos registros dos diários e cartas de Woolf e Mansfield; na segunda, faz-se uma análise de como o deslocamento espaçotemporal da protagonista "Bliss" passa por uma forma consistente de adequar o estilo introspectivo à estética moderna. Metodologicamente, articulam-se conceitos da poética espacial, proposta por Gaston Bachelard (1998), com os deslocamentos heterotópicos, sugeridos por Michel Foucault (2009). Assim, parte-se da premissa de que a autora neozelandesa fez adaptações do estilo de Tchekhov e das preocupações estéticas de sua geração para criar uma narrativa com ritmo poético enxuto e preciso que valoriza a vida como algo imprevisível (WOOLF, 1987, p. 186).

Com base nos estudos comparados, ressalta-se que o contexto moderno questionava a tradição quando problematizava os temas, imagens e estratégias narrativas dos textos canônicos. Sem deixar de lado as experiências anteriores, os escritores modernos queriam acima de tudo um modelo que se adequasse à fragmentação da vida londrina. Portanto, esse processo de renovação das técnicas narrativas e poéticas passa pela exploração da intertextualidade como um mecanismo de criação textual inovador (NITRINI, 2010, p. 162).

Naquele contexto histórico, final da segunda década do século XX, Londres vivia uma ebulição cultural. Mansfield e Woolf escreviam para os jornais da época e entravam em contato com diversas experiências estéticas antes do grande público. Além de seus próprios textos - The voyage out (1915), de Woolf, e Prelude (1918), de Mansfield -, tidos como inovadores, elas tiveram contato com diversas outras experimentações tanto em prosa quanto em poesia.

Virginia Woolf, por exemplo, teve acesso à primeira parte do fabuloso romance Ulisses, de James Joyce. Essa obra representa o ápice da experimentação moderna por trazer a novidade do fluxo de consciência. Essas diferentes inovações estéticas podem ser resumidas como parte da busca constante por novos processos criativos que estavam no ar (LEHMANN, 1989, p. 48).

Com essa preocupação da criação de uma nova estética, Mansfield passa a explorar alguns aspectos do conto de atmosfera com maestria, pois renova esse 
estilo a partir das ambiguidades sentimentais de suas personagens que passam a viver devaneios pessoais em oposição à aparente tranquilidade do cotidiano. Esse respeito à técnica introspectiva, já usada pelos escritores russos, ressalta-se que "a originalidade deixa de ser um raio ou uma iluminação, transformando-se numa metamorfose ou alquimia” (NITRINI, 2010, p. 142).

Assim, entre as marcas do conto de atmosfera e o modelo poético de Mansfield, há uma perspicaz forma de renovar o ritmo narrativo por meio do devaneio espaçotemporal de suas personagens. Nesse processo, os aspectos estéticos desse tipo de conto passam a ser usados como matriz do ritmo moderno. Em alguns momentos, o suspense é usado como parte da progressão poética da narrativa. Nessa "metamorfose textual", Mansfield também leva em conta as especificidades da sociedade londrina, denunciando sua hipocrisia e apego às futilidades.

Como o resultado de um novo modelo literário não nasce do acaso, Mansfield reconhece as diferentes interferências que seu processo criativo sofreu de outros autores. Sendo assim, a intertextualidade faz parte de seu processo de criação, pois, entre seus textos, pode ser vista uma rede de conexões estéticas e culturais que sua arte carrega. Tal intertextualidade é um processo contínuo quando se busca a renovação de um modelo literário (NITRINI, 2010, p. 162). Nesse sentido, suas intertextualidades ressaltam a preocupação de uma artista atenta aos detalhes de sua geração, porquanto se mostra atenta às críticas de seus contemporâneos.

Sua renovação estética pode ser encontrada nas peculiaridades como o devaneio espaçotemporal é construído em "Bliss" (1920). Narrado dentro do espaço da casa londrina, esse conto descreve o estado de devaneio de Bertha, imersa no êxtase da paixão, Pela perspectiva poética, entende-se que "a casa, o quarto, o sótão onde ficamos sozinhos dão os quadros de um devaneio interminável, de um devaneio particular" (BACHELARD, 1998, p. 34). Esse movimento interno da protagonista mostra que ela busca refúgio em um espaço íntimo. Isso é possivel, principalmente, ao se levar em consideração que ela passa por uma heterotopia, deslocamento imaginável (FOUCAULT, 2009, p. 413).

Assim, sua literatura é fruto dessa busca de um modelo poético de narrar. Nesse sentido, os embates críticos e pessoais entre ela e Virginia Woolf dão o tom do quanto esse modelo narrativo fazia parte de suas ambições literárias. As duas tiveram momentos de muitos diálogos, todavia eram "unidas pela devoção à literatura e divididas na sua rivalidade como escritoras, achavam uma à outra sobremodo atraentes, mas muito irritantes" (BELL, 1988, p. 310). Apesar disso, Woolf, por diversas vezes, destaca que a literatura de Mansfield é a que mais se aproxima dos anseios estéticos de sua geração.

As duas escritoras mantinham uma acirrada disputa de prestígio entre os intelectuais londrinos. Virginia Woolf (1987, p. 90) registra em seu Diário, no dia 28 de maio de 1918, o quanto era ambígua sua relação com Mansfield: "A minha teoria é que eu atinjo o que nela é rocha pura, através das muitas brumas e poros que marcam e desorientam a maioria de nossos amigos. É o seu amor pela escrita".

Essa postura de respeito nem sempre é mantida. Em agosto do mesmo ano, Woolf tem uma crise de ciúmes ao comentar o quanto Mansfield se mostra arrogante com o projeto literário que sustenta o conto "Bliss", publicado pela primeira vez em um jornal da época. O comentário deixa transparecer seus ciúmes: 
Atirei o Felicidade ao chão exclamando: "Está arrumada!" Realmente não vejo como se há-de continuar a ter fé nela, quer como mulher quer como escritora, depois de um conto como aquele. Terei infelizmente de aceitar que a sua inteligência é uma fina camada de terra, com uma ou duas polegadas de altura, sobre uma rocha muito estéril (WOOLF, 1987, p. 107).

Retribuindo a falta de gentileza da amiga, no ano seguinte, Mansfield, como crítica literária, produz um texto que questiona o retrocesso de Virgínia Woolf ao retomar estratégias narrativas antigas em Night and day:

Pensamos que esse mundo se desfizera para sempre, que era impossível encontrar no vasto oceano da literatura um navio inconsciente do que andara acontecendo; mas aqui está Night and Day, novo, original - um romance na tradição do romance inglês. No cerne da nossa admiração, ele nos faz sentir velhos $e$ friorentos. Não tínhamos imaginado ver nada assim outra vez (MANSFIELD apud BELL, 1988, p. 347).

Com essa crítica ácida, Mansfield foi implacável com o segundo romance de Virginia, vinculando-a à tradição do romance inglês. No entanto, nem sempre o tom entre as duas era de ataque e confronto. Em visitas sociais, elas trocavam muitas ideias sobre suas experiências literárias, conforme registra Woolf (1987, p. 151), em março de 1919: "tenho com a Katherine o que não tenho com as outras mulheres espertas: uma sensação de bem-estar e interesse que é, suponho, de ela gostar tão genuinamente da nossa preciosa arte, embora de maneira diferente". Dessa forma, elas tinham os mesmos objetivos de experimentar novas formas de narrar.

Virginia Woolf (1987, p. 96) reconhece que a técnica moderna foi bem aplicada ao conto "Prelude", de Mansfield, quando aponta que ele tem "uma certa beleza; um pouco melancólico, reconheço, e bem regado com algumas daquelas suas realidades reles; mas tem a força viva e a autonomia de uma obra de arte". Quando Virginia Woolf lança seu conto experimental "Kew Gardens" (1919), logo recebe elogios particulares da amiga: “tem o 'gesto' exacto; um ponto de viragem" (MANSFIELD apud WOOLF, 1987, p. 206).

Entre acertos e projetos menos sofisticados, portanto, tanto Mansfield quanto Woolf reconhecem a contribuição que cada uma deu para o desenvolvimento da prosa poética de língua inglesa. A seguir, analisa-se o deslocamento espaçotemporal da protagonista de "Bliss" como uma estratégia de modernização da ficção de Katharine Mansfield.

Esse conto narra o estado eufórico de Bertha Young, que apaixonada por Pearl Fulton organiza um jantar para receber amigos. Diante da proximidade do encontro, em estado de êxtase, Bertha se sente "radiante, com lábios trêmulos, sorridentes, grandes olhos escuros e um ar de quem está à espera de que alguma coisa... divina aconteça" (MANSFIELD, 2000, p. 12) ${ }^{1}$. Com esse deslocamento espaçotemporal de Bertha, o conto ressalta o devaneio da protagonista como o fio condutor do conto. Seu estado sentimental é cercado de um tom misterioso. Com isso, o narrador deixa pistas de que nem tudo está tão perfeito assim.

Em seus devaneios, Bertha não consegue observar a realidade, pois se limita aos subterfúgios de sua travessia em buscar da satisfação pessoal. Na contabilidade psicológica, ela soma um bom relacionamento com o marido, Harry, e o prazer social de ter uma filha bonita: "eram realmente bons companheiros",

\footnotetext{
Apesar de ser usada uma versão traduzida do conto "Bliss" como "Felicidade" (MANSFIELD, 2000), neste artigo, optou-se por
} manter o título original por se aproximar mais do estado eufórico e de satisfação que a palavra bliss carrega em língua inglesa. 
além disso, tinham uma linda filha e "não precisavam se preocupar com dinheiro. Tinham esta casa e este jardim, que eram absolutamente satisfatórios" (MANSFIELD, 2000, p. 17).

Consciente da delicadeza do momento - entregar-se cegamente a uma paixão -, Bertha procura justificativas para se manter presa ao cotidiano. Nesse caso, a ideia de estabilidade social funciona como uma âncora, para evitar sua fuga em um devaneio fatal, e assim ela se apega à imagem da casa, que "é um corpo de imagens que dão ao homem razões ou ilusões de estabilidade" (BACHELARD, 1998, p. 36).

Dessa forma, embebida em seus anseios particulares, a protagonista vai transitar pelos espaços da casa como se estivesse refugiada em si. Nessa trajetória interna, ela vive entre o real e o sonho. Assim, constata-se que ela vive entre a utopia de um casamento perfeito e a heterotopia de um amor platônico. Para Michel Foucault (2009, p. 414-415), o que diferencia uma utopia de uma heterotopia é a relação desses espaços com a realidade: "As utopias são os posicionamentos sem lugar real da sociedade", pois "são espaços que fundamentalmente são essencialmente irreais", enquanto as heterotopias são contraposicionamentos reais.

Dentro de seu estado eufórico, Bertha se vê plenamente apaixonada pela família, pelo marido, pela filha pequena, e por sua amiga, pois é um ser "tomado por um sentimento de absoluta felicidade" (MANSFIELD, 2000, p. 11). Assim, "Bliss" descreve uma mulher que vive em uma heterotopia, um deslocamento espaçotemporal afetivo e pessoal. Ela se refugia na sensação de êxtase, que deixa de fora os problemas domésticos. Assim, nas ambivalências desse espaço, seu deslocamento da realidade tem como função mostrar "um espaço de ilusão que denuncia como mais ilusório ainda qualquer espaço real" (FOUCAULT, 2009, p. 420). Essa ilusão pode ser identificada pelo estado eufórico dessa personagem que passa por vários ritmos emocionais.

Em diversas passagens antes do jantar, o estado interior de Bertha é de plenitude e de satisfação e "não sabia como expressar essa sensação, nem o que fazer com ela" (MANSFIELD, 2000, p. 14). Todavia, esse êxtase existencial, por alguns momentos, é cortado por uma desconfiança de Bertha, pois algo a intrigava

[...] embora tivessem estado juntas frequentemente e conversado muito, Bertha não podia ainda ter um conceito formado sobre Pearl Fulton. Até certo ponto, ela era de uma franqueza rara e maravilhosa, mas além desse ponto não passava (MANSFIELD, 2000, p. 23).

Com esse suspense, o conto propõe uma atmosfera de mistério para Pearl. Mesmo desconfiando de algo, Bertha se mantém em seu deslocamento espaçotemporal, que sugere sua fuga da realidade. Tais devaneios rompem com o tempo tradicional para valorizar o tempo interior de seus sentimentos. Nesse caso, o tempo é precário e fútil. (FOUCAULT, 2009, p. 419). Com as pistas do perigo que Bertha está correndo, o narrador deixa pista de que nem tudo está indo tão bem assim.

Além dessa introspecção de Bertha, o modelo poético de Mansfield busca registrar aspectos sociais da família burguesa londrina. Tal perspectiva fica evidente no tom satírico que ela dá ao descrever a excentricidade dos convidados em contraste com a felicidade da protagonista. Entre eles, Norman Knight, que parecia "um macaco muito inteligente, cujo vestido de seda amarela fora feito de cascas de bananas" (MANSFIELD, 2000, p. 18). Entre cenas patéticas e fúteis, os convidados de Bertha vão chegando. 
Sem provas do amor da amiga, suas suspeitas logo são neutralizadas por sua dedicação sentimental. Essa devoção fica explícita na cena do jardim. Após o jantar, o clima entre as duas mulheres ganha um tom de suspense, pois Pearl não corresponde aos anseios de Bertha. Essa perspectiva ameaçadora fica mais forte quando as duas se aproximam do jardim:

Embora o ambiente estivesse tão tranquilo, a pereira parecia a chama de uma vela a alongar-se, apontar para o alto, tremer no ar brilhante, tornando-se cada vez mais alta enquanto elas olhavam, até quase tocar os bordos prateados da lua redonda (MANSFIELD, 2000, p. 23).

Essa imagem da pereira iluminada condensa o ápice do devaneio espacial de Bertha. Nesse caso, a árvore pode ser vista como um limite espiritual dessa mulher que transcende seu corpo físico. Bachelard (1998) ressalta que, na poética do espaço, a árvore é incorporada como um símbolo do limite humano de devaneio. Para ele, "a árvore, como todo ser verdadeiro, é apreendida em seu ser 'sem limite'. Seus limites não passam de acidentes” (BACHELARD, 1998, p. 205). No caso do conto de Mansfield, a pereira é explorada para retratar toda a carga sentimental de Bertha e seu estado de êxtase.

Nesse sentido, cabe destacar que essa árvore tem significados ambíguos enquanto fronteira do deslocamento espaçotemporal de Bertha. No primeiro momento, a força da pereira iluminada pelos raios lunares reforça a completude do êxtase de seus sentimentos. Na sequência, essa grandeza ganha uma dimensão de precipício, quando destaca o polo oposto, a rejeição. Entre a chama interna de Bertha e a solidão da pereira no jardim, a narrativa projeta uma prosa poética que questiona a fugacidade e perenidade das paixões momentâneas.

A impressão grandiosa que a iluminação da pereira provoca em Bertha pode ser traduzida como o ápice de sua heterotopia. Ela rejeita a companhia dos demais para mergulhar em um momento só seu ao lado de sua amada. Com isso, isolada em seu espaço interno, os detalhes externos passam a ser secundários e sem sentido: as visitas excêntricas, os pratos servidos e a indiferença do marido. Assim, a fuga psicológica de Bertha destaca o quanto esses espaços se sobrepõem, projetando-a em um tempo invertido, de um lugar fora de todos os lugares (FOUCAULT, 2009, p. 415).

Com a sugestão de que a protagonista está fora de todas as relações, o conto caminha para a fragmentação de seu êxtase inicial. Esse delicado momento já tinha sido antecipado pela onisciência seletiva, pois há pistas de que a paixão de Bertha não era correspondida. Mesmo assim, essa sensação só passa a fazer parte de seu espaço quando, enfim, suas suspeitas são comprovadas ao ver a troca de carinho entre o marido e a amiga:

Harry com o agasalho de Pearl Fulton nos braços e esta, de costas para ele, com a cabeça inclinada. Ele atirou o casaco para um lado, colocou as mãos nos ombros dela, e virou-se com violência para si. Seus lábios diziam: "eu te adoro”, e Pearl pousou os dedos finos sobre o rosto dele e sorriu aquele seu sorriso sonolento. As narinas de Harry tremiam; os lábios ficaram repuxados para trás, numa crispação horrível, enquanto ele sussurrava: "amanhã" - e, piscando os olhos, Pearl disse: "sim” (MANSFIELD, 2000, p. 26).

Atônita, Bertha continuou sem se mexer na sala até a despedida de Pearl. Com essa descoberta, seu espaço vai encolhendo e ela se isola em um canto da casa, que é um "espaço reduzido onde gostamos de encolher-nos, de recolher-nos em 
nós mesmos, é, para a imaginação, uma solidão" (BACHELARD, 1998, p. 145). Com o desfecho de sua paixão, seu estado de êxtase vai dando lugar ao racional e, aos poucos, vai se voltando para a realidade.

Diante desse novo fato, só lhe restou correr para as janelas largas do jardim e exclamar: "Deus! O que vai acontecer agora?" (MANSFIELD, 2000, p. 27). Com tal deslocamento psicológico da protagonista que perde seu chão, Mansfield conclui seu conto sequestrando a mulher do seu estado interior e lhe despindo socialmente. Com esses acontecimentos, Bertha fica exposta à sua busca interna que vai do estado de euforia ao vazio da traição. Esse final deixa em aberto qual o caminho que ela irá seguir.

Com essa opção espaçotemporal, Mansfield expõe a brevidade das paixões platônicas e a hipocrisia dos casamentos burgueses, deixando uma crítica do quanto um devaneio pessoal é um processo de alienação. Com sua volta ao espaço da sala, Bertha vai se libertando de um estado psicológico doentio, pois nesse processo "o devaneio de habitar se vê logrado. É preciso sempre deixar aberto um devaneio de outro lugar" (BACHELARD, 1998, p. 75).

O modelo de conto moderno de Mansfield, portanto, vai além da classificação "de atmosfera" para valorizar uma narrativa poética, visto que condensa momentos dramáticos da protagonista tanto nos devaneios da paixão como na descoberta da traição. Ao explorar a cena de traição como inversão do êxtase pessoal, Mansfield ressalta a provisoriedade do amor fugaz e das relações sociais.

Em uma sociedade excêntrica e esnobe, a autora ressalta que o rio interno de sentimentos de sua protagonista lhe causa alienação. Com esse movimento da protagonista que, abruptamente, é puxada para a realidade do seu cotidiano, o conto destaca que a heterotopia, como espaço psicológico, também é marcada pela erosão do idealizado, pois "esse espaço que nos corrói e nos sulca é também em si mesmo um espaço heterogêneo" (FOUCAULT, 2009, p. 414).

Identificam-se, portanto, em "Bliss" marcas do modelo moderno de Mansfield a partir da valorização da beleza poética do devaneio, destacando a surpresa da imprevisibilidade das atitudes humanas e da transitoriedade do amor. No conto, essas marcas dão o tom poético tanto do êxtase, quanto do abismo de Bertha.

De volta à realidade, essa mulher se depara com seu mundo em ruínas. Essa construção poética da personagem - fragmentada quando se apaixona, atônita quando é traída - aproxima-se do que Virginia Woolf (apud LEHMANN, 1989, p. 46) defendeu como uma concepção humana moderna para a literatura: "a vida não é uma série de lâmpadas de trole simetricamente dispostas; a vida é um halo luminoso, invólucro semitransparente que nos circunda desde o começo da percepção até o fim".

Com esse estilo de imersão na alma humana, Mansfield rejeita o modelo tradicional de respeito ao tempo externo das personagens e à descrição realista dos costumes sociais. Como visto, nesse conto, o ritmo interno de Bertha dá o tom poético do deslocamento de uma mulher apaixonada que cai em um precipício ao constatar a dupla traição, do marido e da amiga.

Dessa forma, "Bliss" apresenta um modelo ficcional que encanta por trazer algumas variáveis para suas personagens, pois reforça que, apesar de o mundo interior de Bertha ser o eixo da narrativa, há diversos acontecimentos simultâneos à sua volta. Na sua trajetória, essa personagem fica aprisionada a seus anseios e desejos, negando-se a ver as intrigas que fazem parte de seu cotidiano: a educação da filha pela babá, o fingimento do marido, as excentricidades dos convidados. 
Nesse sentido, esse conto se filia à renovação da moderna literatura inglesa, quando incorpora a vontade de inovação estética que estava no ar e era ambicionada pelos artistas da época. Esse processo de construção literária sugere que o "intertexto leva em consideração a sociabilidade da escritura literária, cuja individualidade se realiza até certo ponto no cruzamento particular de escrituras prévias" (NITRINI, 2010, p. 165).

Assim, o modelo espaçotemporal de Mansfield traz uma matriz estética que será muito explorada pelos escritores do século XX. Na perspectiva temporal, ela desenvolve um estilo fragmentado que ressalta o devaneio como marca poética do deslocamento temporal de suas personagens. Na perspectiva espacial, ela reata o fio da narrativa com o social por meio de suas críticas à decadência dos comportamentos burgueses.

\section{KATHERINE MANSFIELD'S MODERN SHORT STORY}

Abstract: This paper presents a study of the spatiotemporal fragmentation of the short story "Bliss", by Katherine Mansfield. Her technique exploits the marks of atmosphere tale through the lean poetic rhythm and the unpredictable, techniques of modern English literature. In the analysis, it emphasizes the spatiotemporal displacement of the protagonist by their personal dilemmas amid values of a futile and talkative London society. Methodologically, it was applied the concepts of modern literature of Virginia Woolf, reverie of Gaston Bachelard, and heterotopia of Michel Foucault.

Keywords: Modern tale. English literature. Katherine Mansfield.

\section{REFERÊNCIAS}

BACHElARD, G. A poética do espaço. Tradução Antônio de Pádua Danesi. São Paulo: Martins Fontes, 1998.

BELL, Q. Virginia Woolf: uma biografia. Tradução Lya Luft. Rio de Janeiro: Guanabara, 1988.

FOUCAULT, M. Outros espaços (Conferência). In: FOUCAULT, M. Estética: literatura e pintura, música e cinema. Organização Manoel Barros da Motta. Tradução Inês Autran Dourado Barbosa. 2. ed. Rio de Janeiro: Fonte Universitária, 2009. LEHMANN, J. Virginia Woolf. Tradução Isabel do Prado. Rio de Janeiro: Jorge Zahar Editor, 1989.

MANSFIELD, K. Felicidade. In: MANSFIELD, K. Felicidade e outros contos. 3. ed. Tradução Julieta Cupertino. Rio Comprido: Revan, 2000.

NITRINI, S. Literatura comparada: história, teoria e crítica. 3. ed. São Paulo: Edusp, 2010.

WOOLF, V. Diário: primeiro volume - 1915-1926. 2. ed. Tradução Maria José Jorge. Lisboa: Bertrand, 1987. 